\title{
Substance Use and Overdose in Public Libraries: Results from a Five-State Survey in the US
}

\author{
Rachel Feuerstein-Simon ${ }^{1}$ (D) Margaret Lowenstein ${ }^{2} \cdot$ Roxanne Dupuis $^{3} \cdot$ Abby Dolan $^{4} \cdot$ Xochitl Luna Marti $^{5}$. \\ Alexandra Harvey ${ }^{1} \cdot$ Heba Ali $^{1}$ - Zachary F. Meisel ${ }^{4,6} \cdot$ David T. Grande $^{4,6} \cdot$ Noah Lenstra ${ }^{7}$. Carolyn C. Cannuscio ${ }^{4,6,8}$
}

Accepted: 3 November 2021 / Published online: 12 January 2022

(c) The Author(s), under exclusive licence to Springer Science+Business Media, LLC, part of Springer Nature 2022

\begin{abstract}
In the U.S., overdoses have become a health crisis in both public and private places. We describe the impact of the overdose crisis in public libraries across five U.S. states, and the front-line response of public library workers. We conducted a cross-sectional survey, inviting one worker to respond at each public library in five randomly selected states (CO, CT, FL, MI, and VA), querying participants regarding substance use and overdose in their communities and institutions, and their preparedness to respond. We describe substance use and overdose patterns, as well as correlates of naloxone uptake, in public libraries. Participating library staff $(\mathrm{N}=356)$ reported witnessing alcohol use $(45 \%)$ and injection drug use $(14 \%)$ in their libraries in the previous month. Across states surveyed, $12 \%$ of respondents reported at least one on-site overdose in the prior year, ranging from a low of $10 \%$ in MI to a high of $17 \%$ in FL. There was wide variation across states in naloxone uptake at libraries, ranging from $0 \%$ of represented libraries in FL to 33\% in CO. Prior on-site overdose was associated with higher odds of naloxone uptake by the library (OR 2.5, 95\% CI 1.1-5.7). Although 24\% of respondents had attended a training regarding substance use in the prior year, over $90 \%$ of respondents wanted to receive additional training on the topic. Public health professionals should partner with public libraries to expand and strengthen substance use outreach and overdose prevention efforts.
\end{abstract}

Keywords Addiction $\cdot$ Public health $\cdot$ Substance abuse $\cdot$ Community health $\cdot$ Public health practice

\section{Introduction}

The United States is in the midst of a drug overdose crisis. As of 2019, over 8 million Americans over the age of 12 years had a substance use disorder (SUD) with illicit drugs and over 14 million had alcohol use disorder [1]. In addition, the most recent available data show that over 80,000 Americans died from drug overdose between May

Rachel Feuerstein-Simon

rachel.feuerstein-simon@pennmedicine.upenn.edu

1 Center for Public Health Initiatives, Perelman School of Medicine, University of Pennsylvania, 3620 Hamilton Walk, Anatomy and Chemistry Building, Room 148, Philadelphia, PA 19104, USA

2 Department of General Internal Medicine, Perelman School of Medicine, University of Pennsylvania, Philadelphia, USA

3 Harvard University, Cambridge, USA

4 Department of Emergency Medicine, Perelman School of Medicine, University of Pennsylvania, Philadelphia, USA
2019 and May 2020 - the highest number of overdose deaths ever recorded in the U.S. [1]. A majority of these deaths were due to opioids, particularly potent synthetic opioids like fentanyl [2]. Despite a modest reduction in overdose deaths in 2018, rates of overdose death escalated alarmingly during the COVID-19 pandemic [2]. There have been concerning increases in the rates of alcohol [3] and stimulant [4] use nationally, and COVID-19 has likely exacerbated

5 San Francisco Department of Public Health, San Francisco, USA

6 Leonard Davis Institute of Health Economics, University of Pennsylvania Perelman School of Medicine, Philadelphia, USA

7 Department of Library and Information Science School of Education, The University of North Carolina at Greensboro (UNCG), Greensboro, USA

8 Department of Family Medicine and Community Health, Perelman School of Medicine, University of Pennsylvania, Philadelphia, USA 
existing drivers of substance use and overdose, including social isolation, decreased access to treatment and harm reduction services, disruptions in regular drug supplies, stress and poverty $[3,4]$.

Substance use and overdose in the U.S. occur in both private and public spaces, such as restaurants, parks, and public libraries [5-7]. Public libraries are of particular interest as they are free and open to all, often prioritize privacy and equity in their mission statements, and frequently serve vulnerable patrons, including those with mental health and SUDs [8-11]. As such, library staff are front-line workers who engage with the public on issues related to substance use and its sequelae. In a statewide survey of public libraries in Pennsylvania conducted in 2016, half of respondents reported providing support to patrons for substance use or mental health in last month, and $12 \%$ reported having had an overdose occur on-site in the prior year [6].

Public libraries across the country are beginning to develop policies and programs in response to substance use. These responses range from installing containers for safe syringe disposal [12] to stocking naloxone-the opioid overdose antidote-and by training their staff in how to administer the medication $[8,11,12]$. Still others have hired or forged partnerships with social workers and social work educators, who assist library staff both in understanding the overdose crisis and in forging community-based responses to it [10]. In 2018, the manufacturer of Narcan ${ }^{\mathrm{TM}}$, the brand name for one formulation of naloxone, began offering two free doses of the medication to any interested public library branch in the U.S. [12]. Professional associations of public librarians have also begun preparing their members to respond to this crisis, with national groups like the U.S. Institute of Museum \& Library Services and regional associations in Ohio, Massachusetts, and Ontario, Canada, all offering public library staff training and guidance on research-based best practices [13-16].

Despite increasing reports of on-site drug use and overdose at libraries and efforts by library organizations and the manufacturer of naloxone to distribute the medication to libraries, questions remain regarding the burden of and response to substance use in U.S. public libraries. The aim of this study was to describe the scope of substance use and overdose in library settings using a cross-sectional survey of public libraries in five states. Results from the study will inform the public health community regarding the scope of the problem in public libraries, libraries' and librarians' capacity to respond, as well as identify areas for public health officials to partner with libraries to help deliver resources and programming.

\section{Methods}

\section{Study Design}

Our team conducted a cross-sectional online survey of public libraries in Colorado (CO), Connecticut (CT), Florida (FL), Michigan (MI), and Virginia (VA). These five states were chosen at random as the first phase of a planned nationwide study regarding the ways public libraries address community health needs.

\section{Survey Design and Administration}

Our team, the Healthy Library Initiative (healthylibrary. org), developed a web-based cross-sectional survey, with 25 items focused on: (1) the frequency and outcomes of substance use and related emergencies in public libraries; (2) public library staff attitudes and concerns regarding substance use in their libraries and communities; (3) public library staff comfort and willingness to engage patrons who use drugs; and (4) implementation of library policies or practices regarding substance use. We also collected brief demographic information about each person responding on behalf of their public library branch. Survey development was informed by a qualitative study of public librarians conducted in 2015 and a single-state survey of public libraries in Pennsylvania conducted in 2017 [6, 17].

Our study sample included all public library branches in the five states. Branches were identified by linking data from multiple sources including: (1) lists from state library directors, (2) membership rosters of the American Library Association, and (3) web searches in order to fully account for every branch in every state studied. We cross-referenced the study databases with the Institute of Museum and Library Services (IMLS) Public Library Survey (PLS), a "census" of all public library branches in the U.S. [18]. The PLS does not include electronic contact information for library branches, so our team collected and verified electronic contact information through a combination of web searches and telephone outreach in order to establish a database of all libraries with active and accurate contact information in the pilot sample.

We emailed survey invitations to 1,695 public libraries across CO, CT, FL, MI, and VA between August 2018 and May 2019. In order to obtain only a single response per library and to verify that the respondent had direct patron contact, we sent a unique survey link to one representative from each library. If the initial respondent did not have direct contact with patrons, they were asked to provide the email address of another contact at their library meeting this criterion. 
The survey was self-administered online by respondents using REDCap, a secure online electronic data capture tool [19].

\section{Data Analysis}

The survey data were analyzed using R v.1.1.45 [20]. We used descriptive statistics to report frequencies of responses. We also examined correlates of naloxone uptake in public libraries, calculating the relative odds of a library having acquired naloxone by the time of the survey, a dichotomous outcome. Model predictors included: report of an overdose on-site in that library in the past year (yes/no) and metrovs. non-metro library location. Metro vs. non-metro libraries were categorized using the "National Center for Health Statistics Urban-Rural Classification Scheme for Counties" [21]. Both crude and adjusted odds ratios were reported.

Table 1 Participant demographics

\begin{tabular}{ll}
\hline Characteristic & No. $(\%)$ \\
\hline Mean age & 51 \\
Sex & \\
Female & $297(83 \%)$ \\
Male & $41(12 \%)$ \\
Other & $3(1 \%)$ \\
Race* & \\
Caucasian & $302(85 \%)$ \\
Black or African American & $13(4 \%)$ \\
Asian & $3(1 \%)$ \\
Other & $15(4 \%)$ \\
Ethnicity & \\
Hispanic or Latino & $15(4 \%)$ \\
Education & \\
High School degree & $19(5 \%)$ \\
Associate's degree & $21(6 \%)$ \\
Bachelor's degree & $43(12 \%)$ \\
Master's degree & $260(73 \%)$ \\
Professional degree & $3(1 \%)$ \\
Doctorate degree & $3(1 \%)$ \\
\hline
\end{tabular}

*Could select more than one answer
We excluded respondents from analyses if they reported no direct patron contact or did not complete the survey. This study was approved by the Institutional Review Board at the University of Pennsylvania.

\section{Results}

We received 356 total responses (response rate $21 \%$ ). As shown in Table 1, the majority of participants were White $(85 \%)$, women $(83 \%)$, and had a master's degree $(73 \%)$.

Across the five participating states, $45 \%$ of responding library staff reported witnessing on-site alcohol use and $14 \%$ reported witnessing on-site injection drug use in the previous month (Table 2 ). There was variation by state in the proportion of participating library staff who witnessed on-site injection drug use, from a high of $36 \%$ in $\mathrm{CO}$, to a low of $7 \%$ in CT.

Across all states, $12 \%$ of respondents reported at least one on-site overdose in the previous year. The highest rate was in FL (17\%), followed by CO (14\%), VA (12\%), CT (11\%), and MI (10\%).

Participating library staff members reported a variety of policies and practices to address substance use and overdose in their libraries (Table 3). Overall, $11 \%$ of libraries stocked naloxone on-site. However, there was wide variation in naloxone uptake among states surveyed, ranging from $33 \%$ in Colorado, to $0 \%$ in Florida. Rates of naloxone uptake among libraries with prior on-site overdoses $(21 \%)$ were higher than the overall average. Further, $12 \%$ of libraries that had experienced an on-site overdose had administered naloxone in the previous year. We saw lower rates of implementation of other practices, including formal guidelines for intervening when people used substances in the library $(10 \%)$, restroom monitoring or time limits (7\%), and safe syringe disposal (6\%) with some variation across states (Table 3 ).

Table 4 shows correlates of naloxone uptake in participating public libraries. Libraries located in metropolitan areas were more likely than those in non-metropolitan areas to stock naloxone on-site. Similarly, libraries that had experienced prior overdoses were more likely than those without prior overdoses to stock naloxone. Library staff from a subset of states (CO, CT, and FL) were asked to rate their level of support for a manufacturer-led
Table 2 Proportion of responding library staff in each state who observed on-site substance use and overdose at their library in the previous month

\begin{tabular}{lllllll}
\hline Substance Type & $\mathrm{CT}(\mathrm{n}=28)$ & $\mathrm{FL}(\mathrm{n}=65)$ & $\mathrm{CO}(\mathrm{n}=36)$ & $\mathrm{VA}(\mathrm{n}=66)$ & $\mathrm{MI}(\mathrm{n}=161)$ & Total $(\mathrm{n}=356)$ \\
\hline Alcohol & $54 \%$ & $52 \%$ & $47 \%$ & $45 \%$ & $39 \%$ & $45 \%$ \\
Injection drugs & $7 \%$ & $14 \%$ & $36 \%$ & $12 \%$ & $11 \%$ & $14 \%$ \\
$\begin{array}{l}\text { Proportion reporting drug overdose on-site in the past year } \\
\text { Overdose }\end{array} 11 \%$ & $17 \%$ & $14 \%$ & $12 \%$ & $10 \%$ & $12 \%$ \\
\hline
\end{tabular}


initiative to distribute two doses of Narcan to any library in the US. On a scale of 1 ("I don't support this at all") to 100 ("I fully support this"), the mean level of reported support was 71, ranging from a high of 77 in $\mathrm{CO}$ to a low of 66 in Florida. Librarian support for this initiative was highly correlated with naloxone uptake (Odds ratio $=18.2$, 95\% CI 2.3-142.8).

We also queried library staff regarding how frequently patrons requested assistance with finding drug and alcohol treatment services in the prior month. Across all participating states, an average of $21 \%$ of library staff reported assisting patrons with finding drug and alcohol treatment services, ranging from a high of $36 \%$ in FL to a low of $14 \%$ in CT. Finally, although $24 \%$ of respondents across all participating states reported having attended at least one training regarding SUD in the past year, $91 \%$ of respondents wanted to receive further training on the topic.

\section{Discussion}

In this five-state survey of public libraries, we found that alcohol and drug use in libraries was common. $45 \%$ of libraries reported on-site drug or alcohol use in the past month, and $12 \%$ of public libraries reported an on-site drug overdose in the prior year. Yet, among libraries there was relatively low uptake of naloxone and other practices to mitigate the impacts of substance use. We did find interest among librarians in receiving additional training to address these issues, suggesting that library staff may recognize both the potential for libraries to assist people struggling with substance use or addiction, and their own limitations in providing that assistance. These findings highlight potential areas for local public health practitioners to partner with libraries.

An important finding was that naloxone uptake was low among libraries located in states with a high burden of overdose morbidity and mortality. For example, FL ranked 22nd nationwide among states for overdose death in 2018, yet none of the 65 participating libraries from FL stocked naloxone at the time of this study [22]. Conversely, naloxone uptake was high in $\mathrm{CO}$, where overdose death rates were lower than those in FL. Past research found that state rates
Table 4 Predictors of naloxone uptake in public libraries

\begin{tabular}{lll}
\hline Exposure & $\begin{array}{l}\text { Unadjusted odds ratio } \\
(95 \% \mathrm{CI})\end{array}$ & $\begin{array}{l}\text { Adjusted odds } \\
\text { ratio (95\% CI) }\end{array}$ \\
\hline $\begin{array}{l}\text { Prior overdose in library } \\
\text { (yes/no) }\end{array}$ & $2.5(1.1-5.7)^{*}$ & $2.3(0.9-5.1)$ \\
$\begin{array}{l}\text { Library located in metro } \\
\text { vs. non-metro area+ }\end{array}$ & $2.2(0.9-5.5)$ & $2.0(0.9-5.6)$ \\
\hline$* p<.05$ & \\
${ }^{+}$Metro vs. non-metro criteria were defined using the "National \\
Center for Health Statistics Urban-Rural Classification Scheme for \\
Counties."
\end{tabular}

of pharmacy-based naloxone dispensing were not correlated with state opioid overdose death rates [23]. Thus, naloxone uptake in public libraries may reflect variation in features of state/local overdose response programs, [24] as well as policy barriers to/facilitators of naloxone access, rather than state-specific overdose death rates [23]. (For example, although anyone in $\mathrm{CO}$ and FL can obtain naloxone at a pharmacy without an individual prescription through a standing order, only CO permits community-based organizations to distribute naloxone directly to lay people [25].) Nonetheless, data from this study indicate high levels of substance use, including injection drug use, in libraries, aligning with national data showing that no state or city is exempt from the effects of addiction [22]. Therefore, it is vital to identify effective strategies to increase the broad adoption of naloxone and overdose reversal training, including public health practitioners offering additional support to libraries in areas with greater barriers to naloxone uptake.

In addition to increasing naloxone uptake in public libraries, library staff would likely benefit from more formalized partnerships with local public health and health care institutions, as well as further training regarding SUD. Over one fifth of library staff in this study reported assisting patrons with finding drug and alcohol treatment services in the prior month. A "secret shopper study" found that a majority of library staff provided some type of referral (e.g., contact information for drug and alcohol commissions) when asked about opioid use disorder (OUD)-related resources. However, there was wide variation in the type of treatment referrals offered [26]. Public health social workers are a

Table 3 Library policies and practices to address on-site substance use

\begin{tabular}{|c|c|c|c|c|c|c|}
\hline Policy & $\mathrm{CO}(\mathrm{n}=36)$ & $\mathrm{CT}(\mathrm{n}=14)$ & FL $(n=65)$ & MI $(n=161)$ & VA $(n=66)$ & Total $(n=356)$ \\
\hline Naloxone (Narcan) stocked on-site in the library & $33 \%$ & $14 \%$ & $0 \%$ & $8 \%$ & $17 \%$ & $11 \%$ \\
\hline Restroom monitoring or time limits & $6 \%$ & $7 \%$ & $3 \%$ & $10 \%$ & $5 \%$ & $7 \%$ \\
\hline Safe syringe disposal facilities & $33 \%$ & $4 \%$ & $3 \%$ & $2 \%$ & $2 \%$ & $6 \%$ \\
\hline $\begin{array}{l}\text { Formal guidelines for intervening when people } \\
\text { are using substances in the library }\end{array}$ & $14 \%$ & $4 \%$ & $12 \%$ & $7 \%$ & $14 \%$ & $10 \%$ \\
\hline
\end{tabular}


promising opportunity to foster connections between the field of public health and the field of public librarianship [8, 33]. Furthermore, enhanced partnership with local public health officials could help libraries develop thoughtfully formulated policies to support people who use drugs (PWUD) $[27,28]$. Like libraries, industries with public or semi-public restrooms-where PWUD often go to inject or use drugsare grappling with the effects of on-site substance use, and experimenting with policies to meet the challenge [5]. Some policies are intended to prevent drug use altogether, such as prohibiting restroom use in restaurants or installing fluorescent blue lights to make it more difficult for people to inject drugs [27]. Other strategies employ a harm reduction approach, such as routine monitoring of restrooms in order to intervene rapidly in the event of an overdose [30, 31]. In this study, in every participating state, less than $10 \%$ of respondents reported that their libraries have restroom monitoring. While this type of policy could be perceived as unwanted surveillance, it also could provide a degree of supervision and protection for PWUD [32-34].

While increasing naloxone uptake in public libraries and establishing thoughtful policies may enhance public library employees' ability to respond to on-site drug use/overdose, these strategies do not address the drivers of public drug use/ overdose [5]. The findings from this study add to the wide body of research supporting the need for supervised consumption facilities (SCFs). SCFs are facilities where PWUD can consume pre-obtained drugs under trained supervision, in clean, sterile environments. Many SCFs also offer medical services including infectious disease screening, substance use treatment referrals, and wound care. Although SCFs in the U.S. are considered unlawful under the federal Comprehensive Drug Abuse Prevention and Control Act of 1970 (CDAPCA), [35] in July 2021, Rhode Island became the first state to legalize SCFs [36]. Research from facilities outside the U.S. found benefits among those who utilized SCF services, including reductions in risk of overdose mortality [37] and risk of HIV and HCV infection, [38, 39] as well as improved access to drug treatment and social services [40, 41]. SCFs were also associated with benefits to the surrounding community including reductions in public drug use, improperly discarded syringes, and ambulance calls $[34,42,43]$. While harm reduction strategies are needed to address the current state of substance use in public libraries, SCFs may offer a promising avenue to divert public drug use, and to ultimately decrease morbidity and mortality among PWUD.

This study has several limitations. Importantly, we have surveyed libraries in five states, which were selected at random, with the intention of building the sample over time to include libraries throughout the U.S. In addition, the libraries that responded to this survey may reflect those differentially engaged in addressing the substance use concerns of their patrons and communities. The response rate to this electronic survey $(21 \%)$ was lower than the $50 \%$ response rate we obtained from a 2016 statewide survey of librarians in Pennsylvania. Future surveys may include telephone outreach to library staff, who are an important group of public service professionals-and potential public health allies.

\section{Conclusion}

Public library staff routinely address issues related to substance use and overdose in their institutions. These findings indicate a need for continued inquiry into the ways libraries nationally are impacted by the overdose crisis, and for evidence-based training and resources for library professionals. This work also highlights the importance of including public libraries as part of a comprehensive public health strategy to address substance use-related morbidity and mortality.

Author Contributions All authors contributed to the study conception and design. Study implementation including survey instruments development, data collection, and data analysis were overseen by Rachel Feuerstein-Simon, Margaret Lowenstein, and Roxanne Dupuis. Survey deployment, data collection, and assistance with analysis were performed by Abby Dolan, Xochitl Luna Marti, Alexandra Harvey, and Heba Ali. Zachary Meisel and David Grandy provided consultation regarding survey instrument development and data analysis. Noah Lenstra provided consultation regarding subject recruitment, data analysis, and manuscript preparation. Carolyn Cannuscio was responsible for overall study oversight and manuscript approval. The first draft of the manuscript was written by Rachel Feuerstein-Simon and all authors commented on previous versions of the manuscript. All authors read and approved the final manuscript.

Funding No funding was obtained to support this project.

Availability of Data and Materials The datasets analyzed during the current study are not publicly available due to subject confidentiality (small sample size and open-ended nature of certain questions could make subjects identifiable).

Code Availability NA.

\section{Declarations}

Conflict of interest The authors have no conflicts of interest to report.

Ethics Approval This research was approved by the Institutional Review Board of the University of Pennsylvania.

Informed Consent Informed consent was obtained from all individual participants included in the study

Consent to Publish NA. 


\section{References}

1. Substance Abuse and Mental Health Services Administration, (SAMHSA). Key substance use and mental health indicators in the united states: Results from the 2019 national survey on drug use and health. Center for Behavioral Health Statistics and Quality, Substance Abuse and Mental Health Services Administration. 2020.

2. CDC Health Alert Network. Increase in fatal drug overdoses across the United States driven by synthetic opioids before and during the COVID-19 pandemic. https://emergency.cdc.gov/han/ 2020/han00438.asp. Updated 2020.

3. Clair, R., Gordon, M., Kroon, M., \& Reilly, C. (2021). The effects of social isolation on well-being and life satisfaction during pandemic. Humanities and Social Sciences Communications., 8(1), 28. https://doi.org/10.1057/s41599-021-00710-3

4. Khatri, U. G., \& Perrone, J. (2020). Opioid use disorder and COVID-19: Crashing of the crises. Journal of Addiction Medicine, 14(4), e6-e7. https://doi.org/10.1097/ADM.0000000000 000684

5. Wolfson-Stofko, B., Bennett, A. S., Elliott, L., \& Curtis, R. (2017). Drug use in business bathrooms: An exploratory study of manager encounters in New York City. The International Journal on Drug Policy, 39, 69-77. https://doi.org/10.1016/j.drugpo.2016. 08.014

6. Whiteman, E. D., Dupuis, R., Morgan, A. U., et al. (2018). Public libraries as partners for health. Preventing Chronic Disease, 15, E64.

7. Schmidt S. 'It is taking people out': More than 70 people overdose on K2 in a single day in New Haven. Aug 16, 2018. Retrieved July 1, 2021 from https://www.washingtonpost.com/news/morni ng-mix/wp/2018/08/16/it-is-taking-people-out-more-than-70-people-overdose-on-k2-in-a-single-day-in-new-haven/.

8. Morgan, A. U., Dupuis, R., DAlonzo B, et al. (2016). Beyond books: Public libraries as partners for population health. Health Affairs, 35(11), 2030-2036.

9. Morgan, A. U., Dupuis, R., Whiteman, E. D., D’Alonzo, B., \& Cannuscio, C. C. (2017). "Our doors are open to everybody": Public libraries as common ground for public health. Journal of Urban Health., 94(1), 1-3. https://doi.org/10.1007/ s11524-016-0118-x

10. Nicholls, M. J., \& Urada, L. A. (2021). Homelessness and polysubstance use: A qualitative study on recovery and treatment access solutions around an urban library in Southern California, USA. Health \& social care in the community. https://doi.org/10. 1111/hsc. 13424

11. Wrigley, J., Kennedy, C., Flaherty, M. G., Ponder, M., Foster, M., \& Akman, J. (2020). A statewide analysis of North Carolina public libraries and their response to the opioid epidemic. Public Library Quarterly., 39(5), 421-433. https://doi.org/10. 1080/01616846.2020.1782701

12. Inklebarger, T. (2018). Company to supply free Narcan to libraries. American Libraries Web site. Retrieved February 10, 2020 from https://americanlibrariesmagazine.org/blogs/the-scoop/ narcan-company-supply-free-narcan-to-libraries/. Updated 2018.

13. Ontario Library Association. Issue brief: Opioids, naloxone, and your local public library. Retrieved Jul 1, 2021 from https:// accessola.com/wp-content/uploads/2020/08/2018-Opioid-InfoB rief.pdf. Updated 2018.

14. OhioNET. Opioids in communities--libraries in response. Retrieved Jul 1, 2021 from https://www.ohionet.org/librariesi nresponse.
15. Allen, S. G., Clark, L., Coleman, M., et al. (2019). Public libraries respond to the opioid crisis with their communities: Summary report. $O C L C$.

16. Coleman, M., Silipigni Connaway, L., \& Morgan, K. (2020). Public libraries respond to the opioid crisis with their communities: Research findings. Collaborative Librarianship., 12, 1.

17. Morgan, A. U., D’Alonzo, B. A., Dupuis, R., et al. (2018). Public library staff as community health partners: Training program design and evaluation. Health Promotion Practice., 19(3), 361-368. https://doi.org/10.1177/1524839917735304

18. Pelczar, M., Frehill, L.M., Williams, K., \& Nielsen E. (2019). Data file documentation: Public libraries in the United States fiscal year 2017. Institute of Museum and Library Services.

19. Harris, P. A., Taylor, R., Thielke, R., Payne, J., Gonzalez, N., \& Conde, J. G. (2009). Research electronic data capture (REDCap) - A metadata-driven methodology and workflow process for providing translational research informatics support. Journal of Biomedical Informatics, 42(2), 377-381. https://doi. org/10.1016/j.jbi.2008.08.010

20. R Core Team. (2021). R: A language and environment for statistical computing. $\mathrm{R}$ foundation for statistical computing, vienna, austria. https://www.R-project.org/.

21. Ingram, D. D., \& Franco, S. J. (2014). 2013 NCHS urbanrural classification scheme for counties. Vital Health Statistics, 2(166), 1-73.

22. Scholl, L., Seth, P., Kariisa, M., Wilson, N., \& Baldwin, G. (2018). Drug and opioid-involved overdose deaths - United States, 2013-2017. MMWR Morbility Mortal Weekly Representation, 67, 5152.

23. Freeman, P. R., Hankosky, E. R., Lofwall, M. R., \& Talbert, J. C. (2018). The changing landscape of naloxone availability in the United States, 2011-2017. Drug and Alcohol Dependence, 191, 361-364.

24. Feuerstein-Simon, R., Lowenstein, M., Sharma, M., Dupuis, R., Luna Marti, X., \& Cannuscio, C. (2020). Local health departments and the implementation of evidence-based policies to address opioid overdose mortality. Substance Abuse., 41(4), 468-474. https://doi.org/10.1080/08897077.2019.1709250

25. Lieberman, A., \& Davis, C. (2021). Legal interventions to reduce overdose mortality: Naloxone access laws. The Network for Public Health Law.

26. Wong, V., Cannuscio, C. C., Lowenstein, M., Feuerstein-Simon, R., Graves, R., \& Meisel, Z. F. (2021). How do public libraries respond to patron queries about opioid use disorder? A secret shopper study. Null. https://doi.org/10.1080/08897077.2021. 1900980

27. Lowenstein, M., Feuerstein-Simon, R., Sheni, R., et al. (2019). Public libraries as partners in confronting the overdose crisis: A qualitative analysis. Substance Abuse. https://doi.org/10.1080/ 08897077.2019.1691129

28. Lowenstein, M., Feuerstein-Simon, R., Dupuis, R., et al. (2020). Overdose awareness and reversal trainings at philadelphia public libraries. American Journal of Health Promotion., 35(2), 250 254. https://doi.org/10.1177/0890117120937909

29. Buchheit, B. M., Crable, E. L., Lipson, S. K., Drainoni, M., \& Walley, A. Y. (2021). "Opening the door to somebody who has a chance" - the experiences and perceptions of public safety personnel towards a public restroom overdose prevention alarm system. International Journal of Drug Policy., 88, 103038. https://doi.org/ 10.1016/j.drugpo.2020.103038

30. Wallace, B., Pauly, B., Barber, K., Vallance, K., Patterson, J., Stockwell, T. Every washroom: De facto consumption sites in the epicenter of an overdose public health emergency. https://www. 
uvic.ca/research/centres/cisur/assets/docs/bulletin-15-every-washr oom-overdose-emergency.pdf. Updated 2016.

31. Walley, A. Y., Xuan, Z., Hackman, H. H., et al. (2013). Opioid overdose rates and implementation of overdose education and nasal naloxone distribution in Massachusetts: Interrupted time series analysis. BMJ: British Medical Journal., 346(7894), 13.

32. Ford, A. (2017). Saving lives in the stacks. American Libraries, 48(9/10), 44-49.

33. Vallejo, M. (2018). Safer bathrooms in syringe exchange programs: Injecting progress into the harm reduction movement. Columbia Law Review, 118(4), 1185-1224.

34. Salmon, A. M., van Beek, I., Amin, J., Kaldor, J., \& Maher, L. (2010). The impact of a supervised injecting facility on ambulance call-outs in Sydney, Australia. Addiction, 105(4), 676-683. https:// doi.org/10.1111/j.1360-0443.2009.02837.x

35. Roberts C. How supervised injection sites can help address the overdose crisis. Harvard Law The Petrie-Flom Center Web site. https://blog.petrieflom.law.harvard.edu/2021/03/26/supervisedinjection-sites-overdose-crisis/. Updated 2021.

36. Jaeger K. Rhode Island makes history by legalizing safe consumption sites. Filter. Retrieved Jul 21, 2021. https://filtermag. org/rhode-island-safe-consumption-site-bill/.

37. Marshall, B. D., Milloy, M. J., Wood, E., Montaner, J. S., \& Kerr, T. (2011). Reduction in overdose mortality after the opening of North America's first medically supervised safer injecting facility: A retrospective population-based study. Lancet, 377(9775), 1429-1437. https://doi.org/10.1016/S0140-6736(10)62353-7

38. Salmon, A. M., van Beek, I., Amin, J., Grulich, A., \& Maher, L. (2009). High HIV testing and low HIV prevalence among injecting drug users attending the Sydney medically supervised injecting centre. Australian and New Zealand Journal of Public Health, 33(3), 280-283. https://doi.org/10.1111/j.1753-6405. 2009.00389.x

39. Pinkerton, S. D. (2011). How many HIV infections are prevented by Vancouver Canada's supervised injection facility? The International Journal on Drug Policy, 22(3), 179-183. https://doi.org/ 10.1016/j.drugpo.2011.03.003

40. Potier, C., Laprévote, V., Dubois-Arber, F., Cottencin, O., \& Rolland, B. (2014). Supervised injection services: What has been demonstrated? A systematic literature review. Drug and Alcohol Dependence, 145, 48-68.

41. DeBeck, K., Kerr, T., Bird, L., et al. (2011). Injection drug use cessation and use of North America's first medically supervised safer injecting facility. Drug and Alcohol Dependence, 113(2-3), 172-176. https://doi.org/10.1016/j.drugalcdep.2010.07.023

42. Stoltz, J., Wood, E., Small, W., et al. (2007). Changes in injecting practices associated with the use of a medically supervised safer injection facility. Journal of Public Health (Oxford, England), 29(1), 35-39. https://doi.org/10.1093/pubmed/fdl090

43. Wood, E., Kerr, T., Small, W., et al. (2004). Changes in public order after the opening of a medically supervised safer injecting facility for illicit injection drug users. CMAJ, 171(7), 731-734.

Publisher's Note Springer Nature remains neutral with regard to jurisdictional claims in published maps and institutional affiliations. 